\title{
PERSEPSI MASYARAKAT TERHADAP PEMBANGUNAN PENANGKARAN RUSA SAMBAR (Cervus unicolor Kerr, 1792) DI KHDTK SAMBOJA, KALIMANTAN TIMUR (The Community's Perception on Sambar Deer (Cervus unicolor Kerr, 1792) Captive Breeding Establishment in Forest Area in Special Purposes (FASP) Samboja, East Kalimantan)*
}

\author{
Tri Sayektiningsih ${ }^{1}$, Tri Atmoko ${ }^{2}$, dan/and Amir Ma’ruf ${ }^{3}$ \\ Balai Penelitian Teknologi Konservasi Sumberdaya Alam \\ Jl. Soekarno-Hatta Km 38, Balikpapan, Kalimantan Timur; email: ${ }^{11}$ t. sayekti@yahoo.com, \\ ${ }^{2)}$ tri.atmoko@forda-mof.org, ${ }^{3)}$ drh.amirmaruf@yahoo.com \\ *Diterima : 21 Maret 2011; Disetujui : 8 April 2014
}

\begin{abstract}
Community's perception is valuable information to consider in developing sambar deer captive breeding. The aim of this research was to obtain the community's perception on sambar deer captive breeding establishment in Forest Area in Special Purposes (FASP) Samboja. The research was conducted in September 2010 in Semoi Dua village, Penajam Paser Utara District, East Kalimantan. Primary data was obtained through structural guided interview. Random sampling was used to obtain respondents. Overall, respondents were 30 head of households who lived in RT 13 and 14, Semoi Dua village. The result showed that community's perception on sambar deer captive breeding establishment in FASP Samboja was rated as medium. They supported the project as long as no disturb to their activities within FASP Samboja. Based on multiple regression analysis, the main factor affected community's perception was respondent's income. Recruitment of local people as captivity workers may be the solution at oncereducing farming activities in the FASP Samboja.
\end{abstract}

Keywords: Perception, Cervus unicolor, Forest Area in Special Purposes (FASP) Samboja, captive breeding

\begin{abstract}
ABSTRAK
Informasi mengenai persepsi masyarakat di sekitar Kawasan Hutan Dengan Tujuan Khusus (KHDTK) Samboja bermanfaat sebagai bahan pertimbangan dalam pembangunan penangkaran rusa sambar (Cervus unicolor Kerr, 1792) di kawasan tersebut. Penelitian ini bertujuan untuk mendapatkan informasi tentang persepsi dan kondisi sosial ekonomi masyarakat terhadap pembangunan penangkaran rusa sambar di KHDTK Samboja dan sekitarnya. Penelitian dilaksanakan pada bulan September 2010 di Desa Semoi Dua, Kabupaten Penajam Paser Utara, Kalimantan Timur. Pengumpulan data primer dilakukan melalui wawancara dengan responden terpilih menggunakan panduan. Penentuan responden dilakukan secara acak. Responden terdiri dari 30 kepala rumah tangga yang bermukim di RT 13 dan RT 14 Desa Semoi Dua. Hasil penelitian menunjukkan bahwa persepsi masyarakat Desa Semoi Dua terhadap pembangunan penangkaran rusa sambar kategori sedang, yaitu masyarakat mendukung pembangunan penangkaran rusa sambar, tetapi khawatir apabila kegiatan tersebut dapat menganggu aktivitas berladang mereka dan membatasi akses mereka memperluas lahan garapan di dalam kawasan KHDTK. Faktor yang mempengaruhi persepsi masyarakat terhadap pembangunan penangkaran rusa sambar adalah pendapatan responden. Perekrutan masyarakat lokal sebagai pekerja penangkaran dapat menjadi solusi sekaligus mengurangi aktivitas berladang di dalam kawasan KHDTK Samboja.
\end{abstract}

Kata kunci: Persepsi, Cervus unicolor, KHDTK Samboja, penangkaran

\section{PENDAHULUAN}

Rusa sambar (Cervus unicolor Kerr, 1792) adalah salah satu jenis satwa yang dilindungi dan masuk dalam kategori rentan terhadap kepunahan (Peraturan Pemerintah Nomor 7 Tahun 1999; IUCN,
2012). Ancaman kepunahan rusa sambar disebabkan oleh perburuan liar yang dipicu oleh permintaan daging rusa yang tinggi dari masyarakat (Ma'ruf et al., 2006; Garsetiasih \& Takandjandji, 2007). Perburuan yang berlebihan merupakan 
penyebab utama menurunnya populasi rusa sambar di habitat alaminya. Kondisi demikian diperparah oleh kemampuan reproduksi yang terbatas (Suba et al., 2010) dan kerusakan habitat (Manshur, 2011).

Kondisi di atas perlu diimbangi dengan upaya pelestarian secara ex-situ, salah satunya dengan membangun penangkaran. Upaya penangkaran rusa sambar untuk pelepasliaran masih terbatas. Penangkaran rusa sambar di Pulau Jawa hanya tercatat tiga penangkaran dengan 31 individu rusa sedangkan di Kalimantan Timur terdapat satu proyek percontohan penangkaran rusa sambar yaitu di Kabupaten Penajam Paser Utara, Kalimantan Timur namun lebih mengarah untuk penyediaan bibit dan tujuan komersial (Santoso \& Fanani, 2009; Atmoko, 2007).

Kawasan Hutan Dengan Tujuan Khusus (KHDTK) sebagai hutan penelitian merupakan faktor penunjang yang sangat penting dalam peningkatan kegiatan penelitian dan pengembangan (Mindawati, 2006), salah satunya sebagai lokasi penangkaran rusa sambar. Luas KHDTK Samboja adalah 3.504 ha dengan topografi yang bervariasi dan terdiri atas beberapa tipe ekosistem, di antaranya adalah hutan hujan tropis primer, hutan sekunder bekas terbakar, dan padang alang-alang. Di KHDTK ini juga melintas Sungai Saka Kanan, Sungai Petatai, dan Sungai Muarawali (Gunawan et al., 2005).

Pembangunan penangkaran rusa sambar di KHDTK Samboja ditujukan untuk pelepasliaran atau peningkatan populasi di alam. Pemeliharaan rusa di KHDTK Samboja mengadopsi sistem semi intensif atau mini ranch. Menurut Setio et al. (2011) pemeliharaan rusa dengan sistem semi intensif dilakukan dengan cara memelihara rusa pada suatu lokasi penggembalaan yang luas dan dikelilingi pagar. Rusa dibiarkan merumput sendiri tetapi kadang-kadang pakan dipasok dari luar apabila pakan di dalam tidak mencukupi.

Informasi tentang kondisi sosial ekonomi dan persepsi masyarakat sekitar KHDTK terhadap pembangunan penangkaran rusa sambar penting diketahui, hal itu dikarenakan dukungan masyarakat sekitar sangat menunjang keberhasilan kegiatan penangkaran tersebut (Takandjandji et al., 2011). Masyarakat dengan kondisi sosial, ekonomi dan budaya yang berbeda akan memberikan tanggapan, penilaian dan persepsi yang berbeda. Penelitian ini bertujuan untuk mendapatkan informasi mengenai kondisi sosial ekonomi dan persepsi masyarakat yang bermukim di sekitar KHDTK Samboja terhadap kegiatan dan pembangunan penangkaran rusa sambar dan faktor-faktor yang mempengaruhinya. Hasil penelitian ini diharapkan dapat bermanfaat sebagai salah satu bahan pertimbangan dalam menentukan kelayakan penangkaran rusa sambar di KHDTK Samboja.

\section{BAHAN DAN METODE}

\section{A. Waktu dan Lokasi Penelitian}

Penelitian dilakukan di Desa Semoi Dua, Kecamatan Sepaku, Kabupaten Penajam Paser Utara, Provinsi Kalimantan Timur pada bulan September 2010. Desa Semoi Dua memiliki luas 6.000 ha dan berbatasan langsung dengan KHDTK Samboja.

\section{B. Bahan dan Alat Penelitian}

Obyek penelitian adalah masyarakat yang bermukim di Rukun Tetangga (RT) 13 dan RT 14, Desa Semoi Dua, Kecamatan Semoi, Kabupaten Penajam Paser Utara. Peralatan penelitian meliputi alat perekam, kamera, dan alat tulis. Bahan penelitian adalah panduan wawancara. 


\section{Metode Penelitian}

\section{Pengumpulan Data}

Pengumpulan data primer dilakukan melalui wawancara terstruktur menggunakan panduan (Singarimbun \& Effendi, 1995). Penentuan responden dilakukan secara acak yang terdiri atas 30 kepala keluarga (KK). Data sekunder diperoleh melalui studi pustaka dan laporan hasil-hasil penelitian yang berkaitan.

\section{Analisis Data}

Analisis data dilakukan dengan dua metode, meliputi:

\section{a. Analisis Tingkat Pengharkatan}

Analisis tingkat pengharkatan digunakan untuk mengetahui tingkat persepsi masyarakat. Nilai dari persepsi akan dibagi dalam tiga tingkatan, yaitu baik $((\mathrm{X}>(\mathrm{M}+\mathrm{SD}))$, sedang $((\mathrm{M}-\mathrm{SD}) \leq \mathrm{X} \leq$ $(\mathrm{M}+\mathrm{SD}))$, dan buruk $((\mathrm{X}<(\mathrm{M}-\mathrm{SD}))$ (Saragih, 2007).

\section{b. Analisis Regresi Berganda}

Variabel penelitian dikelompokkan menjadi dua, yaitu variabel terikat (Y) adalah persepsi masyarakat dan variabel bebas $(\mathrm{X})$ yang terdiri atas $\mathrm{X}_{1}$ (tingkat pendidikan formal), $\mathrm{X}_{2}$ (tingkat pendidikan non formal), $\mathrm{X}_{3}$ (pendapatan), $\mathrm{X}_{4}$ (jumlah tanggungan keluarga), $\mathrm{X}_{5}$ (luas lahan garapan), dan $\mathrm{X}_{6}$ (lama tinggal). Analisis regresi berganda menggunakan persamaan sebagai berikut (Sugiyono \& Wibowo, 2004):

$\mathrm{Y}=\mathrm{b}_{0}+\mathrm{b}_{1} \mathrm{X}_{1}+\mathrm{b}_{2} \mathrm{X}_{2}+\mathrm{b}_{3} \mathrm{X}_{3}+\mathrm{b}_{4} \mathrm{X}_{4}+\mathrm{b}_{5} \mathrm{X}_{5}+$ $\mathrm{b}_{6} \mathrm{X}_{6}$

Dimana:

Y : Persepsi masyarakat

$\mathrm{b}_{0}$ : intercept

$\mathrm{b}_{1}$ : rataan perubahan $\mathrm{Y}$ per unit akibat perubahan $\mathrm{X}_{1}$ sebesar 1 unit bila $\mathrm{X}_{2}, \mathrm{X}_{3}$ dan seterusnya konstan (pengertian yang sama juga berlaku untuk $b_{2}$ sampai $b_{6}$ ).

Pengaruh signifikansi keenam faktor tersebut terhadap persepsi diketahui dengan melakukan uji-F. Hipotesis yang digunakan dalam uji-F adalah:

$\mathrm{H}_{0}$ : Tidak ada pengaruh secara signifikan dari keenam faktor secara bersamasama terhadap persepsi.

$\mathrm{H}_{1}$ : Ada pengaruh secara signifikan dari keenam faktor secara bersama-sama terhadap persepsi.

Untuk mengetahui pengaruh setiap faktor secara parsial terhadap persepsi, dilakukan uji-t. Hipotesis yang digunakan dalam uji-t adalah:

$\mathrm{H}_{0}$ : Tidak ada pengaruh secara signifikan dari faktor ke-i terhadap persepsi.

$\mathrm{H}_{1}$ : Ada pengaruh secara signifikan dari faktor ke-i terhadap persepsi.

Analisis regresi berganda dilakukan dengan bantuan program SPSS 17.0.

\section{HASIL DAN PEMBAHASAN}

\section{A. Karakteristik Responden}

Responden yang bermukim di RT 13 dan RT 14 Desa Semoi Dua sebagian besar (60\%) berusia antara 30-50 tahun. Prasetya (2010) menyatakan rentang usia 30-50 tahun merupakan rentang usia produktif, di mana mereka dapat berkarya dan bekerja secara optimal. Umumnya, responden dengan usia tersebut berkewajiban memenuhi kebutuhan hidup sehari-hari dengan bekerja antara lain di bidang pertanian.

Mayoritas (66,67\%) mengeyam pendidikan formal yang pernah ditempuh antara 6-9 tahun dengan jenjang pendidikan SD. Menurut beberapa responden, setelah lulus sekolah dasar, mereka mengikuti orang tua pindah ke Desa Semoi Dua. Sebagian responden pernah mendapat pendidikan non formal, terutama pada saat mereka tergabung dalam kelompok tani. Pendidikan non formal yang pernah diikuti oleh responden adalah pelatihan, penyuluhan atau kursus dengan frekuensi antara 1-3 kali. Salah satu pendidikan non formal yang diikuti oleh responden adalah pelatihan budidaya lada yang 
diselenggarakan oleh Dinas Perkebunan Kabupaten Penajam Paser Utara.

Jumlah anggota keluarga yang menetap dan menjadi tanggungan $\mathrm{KK}$ berkisar antara 3-5 orang, dengan ratarata tiga jiwa per keluarga. Umumnya yang masih menjadi tanggungan adalah anak-anak yang masih bersekolah di tingkat SD dan Sekolah Menengah Pertama (SMP).

Masa mukim responden di Desa Semoi Dua rata-rata 29,7 tahun. Sebagian besar $(96,67 \%)$ masa mukim responden lebih dari 10 tahun. Responden adalah transmigran yang berasal dari Tasikmalaya dan Tuban. Mereka datang ke Desa Semoi Dua pada tahun 1978-1982 (Falah et al., 2005).

\section{B. Kondisi Sosial dan Ekonomi Masyarakat Desa Semoi Dua}

Terbentuknya komunitas masyarakat di Desa Semoi Dua berkaitan dengan adanya program transmigrasi dari pemerintah pusat. Transmigran pertamakali datang dari Jawa Barat (Tasikmalaya) pada tahun 1978, disusul oleh transmigran bedol desa dari Tuban, Jawa Timur pada tahun 1982 (Falah et al., 2005). Pada saat penelitian ini dilakukan, masyarakat transmigran merasa betah tinggal di Desa Semoi Dua dengan alasan taraf hidup meningkat dibandingkan saat tinggal di Jawa. Sekarang mereka dapat memperoleh pekerjaan yang layak dan membiayai sekolah anak sampai jenjang pendidikan menengah dan tinggi.

Masyarakat Desa Semoi Dua saat ini terdiri atas beberapa etnis, seperti Jawa, Sunda, Bugis, Madura, Bali, Banjar, dan Batak. Sebagian besar mata pencaharian masyarakat adalah bertani. Sampai saat ini terdapat kurang lebih 19 kelompok tani yang dibina oleh Dinas Pertanian Kabupaten Penajam Paser Utara. Setiap dua RT dibentuk satu kelompok tani yang beranggotakan sekitar 26 orang. Kelompok tani yang ada antara lain kelompok tani yang mengusahakan lada 146
(Piper nigrum L.), sengon (Paraserianthes falcataria (L.) I.C.Nielsen), dan karet (Hevea brasiliensis (Willd.ex A.Juss.) Müll.Arg.).

Kehidupan masyarakat di Desa Semoi Dua sangat bergantung pada sumberdaya alam di sekitarnya. Masyarakat memanfaatkan kayu dan hasil hutan non kayu untuk mencukupi kebutuhan hidupnya. Masyarakat juga bercocok tanam, baik pada lahan milik maupun lahan negara. Status lahan yang dikelola oleh masyarakat umumnya adalah hak milik, namun apabila luasannya sudah tidak mencukupi, maka sebagian dari mereka masuk ke dalam KHDTK Samboja.

Sebesar (80\%) responden memiliki lahan garapan lebih dari 1,5 ha. Sebagai peserta transmigrasi, reponden telah dibekali lahan oleh pemerintah seluas dua hektar, di mana 0,75 ha digunakan untuk rumah dan pekarangan, sisanya untuk berladang (Falah et al., 2005). Masyarakat mengusahakan kebunnya sesuai sistem yang diadopsi dari kampung halamannya, yaitu menanami dengan padi gunung (tadah hujan), palawija, buah dan sayur-mayur. Jenis tanaman lain yang diusahakan oleh masyarakat antara lain lada, karet, sengon, sawit (Elaeis guineensis Jacq.), durian (Durio zibethinus L.), dan jati (Tectona grandis L.f.). Masyarakat di Desa Semoi Dua adalah petani menetap. Lahan yang telah digarap tetap dipelihara tetapi mereka juga membuka lahan di tempat lain. Saat ini luas lahan masyarakat umumnya bertambah. Hal ini disebabkan oleh kebutuhan masyarakat yang terus meningkat.

Masyarakat yang berprofesi sebagai petani, di mana sumber penghasilan utama responden berasal dari penjualan hasil panen seperti lada, palawija, buah dan sayur-mayur. Walaupun demikian, sebagian kecil responden memperoleh penghasilan dari pekerjaan lain, seperti buruh bangunan dan penjahit. Penghasilan responden termasuk rendah, 
yaitu kurang dari Rp 500.000,-/bulan. Kecilnya penghasilan responden disebabkan sebagian besar dari mereka lebih mengutamakan lada sebagai komoditi panen andalan sehingga tanaman lain kurang diperhatikan dalam perawatannya. Pada saat penelitian berlangsung, banyak tanaman lada yang terserang virus. Hal ini diduga mengakibatkan kecilnya pendapatan yang diperoleh.

Masyarakat biasanya menjual lada hasil panen kepada tengkulak dengan harga Rp 35.000,00/kg, dalam setahun biasanya lada dipetik empat sampai dengan lima kali. Hasil panen padi gunung oleh masyarakat tidak dijual namun untuk memenuhi kebutuhan sendiri. Berdasarkan uraian di atas tampak bahwa masyarakat di Desa Semoi Dua mengandalkan hasil panen dari beberapa lahan budidaya. Kondisi demikian dapat pula dijumpai di daerah penyangga Taman Nasional Bukit Tiga Puluh, Jambi. Jenis lahan budidaya yang dimiliki oleh masyarakat di daerah tersebut umumnya bervariasi, karena untuk memenuhi kebutuhan hidup tidak dapat hanya mengandalkan hasil panen dari satu jenis lahan budidaya saja (Kuswanda, 2006).

\section{Persepsi Masyarakat}

\section{Pengetahuan tentang Rusa Sambar}

Menurut sebagian besar (80\%) responden, saat ini sudah semakin sulit menemukan rusa sambar di dalam hutan (Gambar 1). Sebanyak 86,67\% responden menyatakan bahwa penurunan populasi tersebut diduga disebabkan perburuan liar yang menggunakan perangkap atau jerat (Gambar 2).

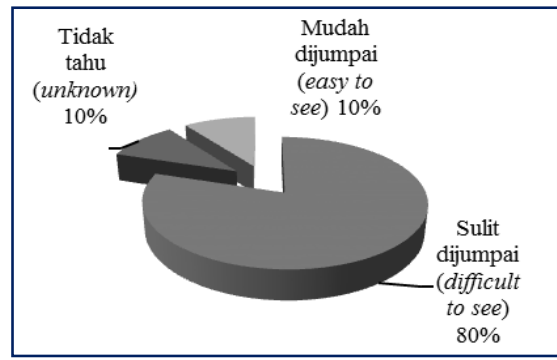

Gambar (Figure) 1. Kondisi rusa sambar di alam saat ini (Sambar deer's state of affairs in nature at the present time)
Daging rusa hasil buruan selanjutnya dijual di pasar tradisional dengan harga Rp 35.000,00-45.000,00/kg, sedangkan daging yang sudah digiling dijual dengan harga Rp 60.000,00/kg. Selain akibat perburuan, penurunan populasi diduga juga disebabkan kerusakan habitat (76,77\%). Masyarakat menyadari kondisi KHDTK Samboja yang sering mengalami kebakaran pada musim kemarau juga berpengaruh terhadap penurunan populasi rusa sambar. Kebakaran tersebut, menurut masyarakat dapat merusak habitat rusa sambar, seperti pohon-pohon pelindung (shelter) dan sumber pakan (Gambar 3).

Sebanyak 90\% responden mengeta-hui bahwa rusa sambar termasuk satwa yang dilindungi, sehingga tidak boleh diburu. Responden menyebutkan bahwa rusa sambar merupakan satwa yang dilindungi oleh pemerintah, mereka tidak menyebutkan bahwa satwa tersebut dilindungi oleh undang-undang (Gambar 4).

\section{Aspek Pembangunan Penangkaran Rusa sambar (Cervus unicolor (Kerr, 1792))}

Hampir semua responden (96,67\%) berpendapat bahwa pembangunan penangkaran rusa sambar di KHDTK Samboja merupakan salah satu upaya yang penting dilakukan untuk melestarkan satwa tersebut. Mereka berharap dengan pembangunan penangkaran tersebut anak cucu mereka masih dapat mengetahui rusa sambar di masa depan (Gambar 5).

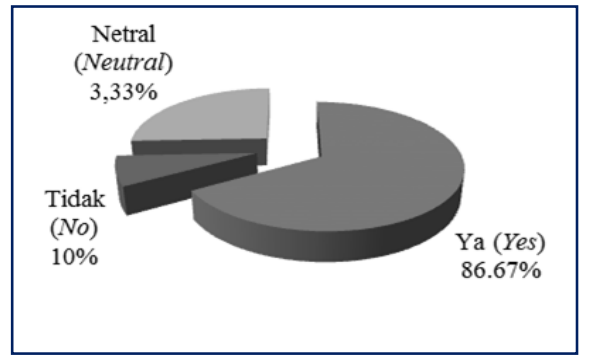

Gambar (Figure) 2. Penurunan populasi rusa sambar karena perburuan (Declining of sampq4 deer's population due to hunting activities) 


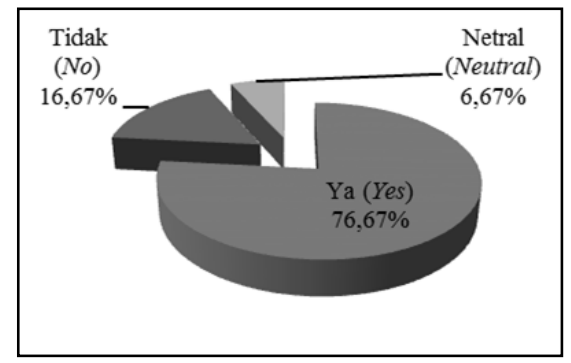

Gambar (Figure) 3. Penurunan populasi rusa sambar, karena kerusakan habitat (Declining of sambar deer's population due to habitat disturbances)

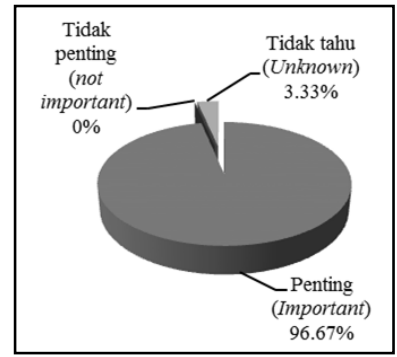

Gambar (Figure) 5. Pentingnya pemba-ngunan penangkaran rusa sambar di KHDTK Samboja (The important of sambar deer's captive breeding establishment in KHDTK Samboja)

Pembangunan penangkaran rusa sambar diyakini dapat memberikan dampak positif terhadap kemajuan desa, salah satunya dapat membuka lapangan kerja baru (80\%) (Gambar 6). Masyarakat berharap pembangunan penangkaran rusa sambar di KHDTK Samboja dapat melibatkan mereka, sejak dari proses perencanaan sampai dengan pelaksanannya (86,67\%) (Gambar 7). Upaya pelibatan dan partisipasi masyarakat menjadi hal yang penting dan harus

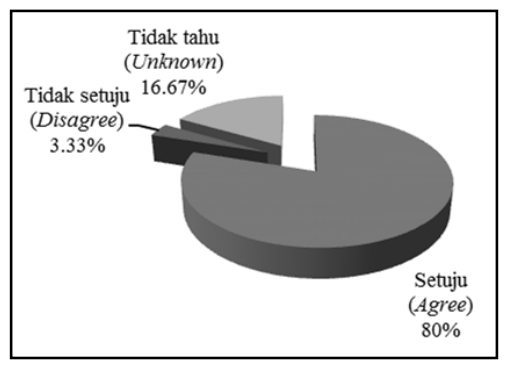

Gambar (Figure) 6. Pembangunan penangkaran akan membawa dampak positif (Captive breeding establishment bring positive impact)

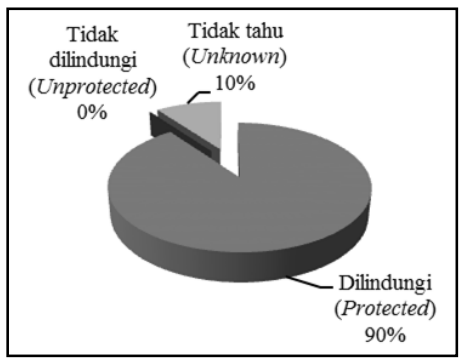

Gambar (Figure) 4. Status konservasi rusa sambar (Sambar deer's conservation status)

diperhatikan dalam rencana pengelolaannya.

Berdasarkan skoring, persepsi masyarakat Desa Semoi Dua mengenai pembangunan penangkaran rusa sambar tergolong "sedang". Masyarakat mendukung pembangunan penangkaran rusa sambar, tetapi sedikit khawatir jika pembangunan penangkaran tersebut mengganggu aktivitas berladang mereka. Strategi yang dapat diterapkan untuk menjawab kekhawatiran masyarakat adalah melibatkan masyarakat dalam setiap tahapan perencanaan sampai dengan pelaksanaannya. Nantinya, masyarakat diberikan kesempatan untuk terlibat langsung sebagai tenaga harian dalam perawatan rusa atau mencari pakan bagi rusa di penangkaran. Upaya ini akan mengurangi dan mengalihkan aktivitas masyarakat membuka lahan untuk berladang di KHDTK Samboja sekaligus memberikan lapangan kerja baru bagi masyarakat.

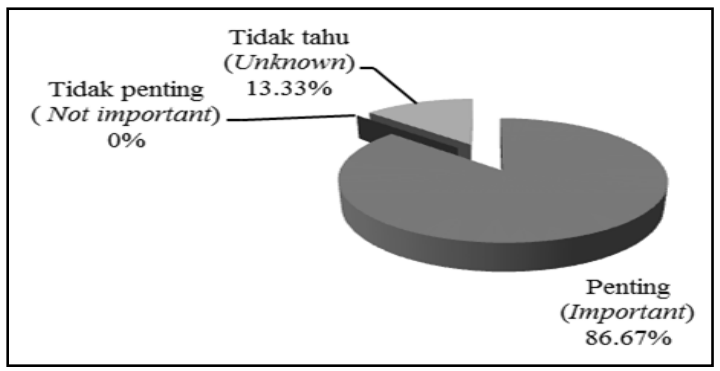

Gambar (Figure) 7. Pentingnya partisipasi masyarakat sekitar (The important of community participation) 
Sebanyak tujuh responden (23,33\%) berpendapat bahwa pembangunan penangkaran dapat berdampak negatif bagi masyarakat. Apabila dirinci, alasan kekhawatiran dari ketujuh responden tersebut antara lain membatasi akses masyarakat untuk membuka ladang baru di dalam kawasan $(57,14 \%)$ dan adanya kemungkinan perusakan tanaman milik masyarakat apabila rusa lepas (42,85\%). Kekhawatiran tersebut merupakan implikasi dari perilaku sebagian masyarakat yang masih masuk ke hutan yang berarti memungut hasil hutan dan berladang (Falah et al., 2005).

Persepsi sebagian masyarakat yang beranggapan bahwa pembangunan penangkaran rusa sambar membawa dampak negatif dan cenderung menolaknya juga dipicu oleh adanya upaya penguasaan lahan dan illegal logging (Yassir, 2013, komunikasi pribadi; Riana, 2013). Meningkatnya upaya penguasaan lahan dan illegal logging diindikasikan dengan semakin luasnya tutupan lahan semak belukar, pertanian campur semak, dan perkebunan dalam kurun waktu 2010-2013. Semak belukar mengalami perubahan luasan dari 1033,1 ha menjadi 1047,1 ha (penambahan luas sebesar 14,0 ha). Pertanian campur semak mengalami perubahan luasan dari 445,6 ha menjadi 462,7 ha (penambahan luas sebesar 17,1 ha). Kebun masyarakat mengalami perubahan luasan dari 60,3 ha menjadi 63,8 ha (penambahan luas sebesar 3,5 ha).

Kategori persepsi responden mengenai pembangunan penangkaran rusa sambar di KHDTK Samboja berikut jumlah dan persentasenya disajikan dalam Tabel 1 .

\section{Faktor-faktor yang Mempengaruhi Persepsi Masyarakat}

Persamaan regresi berganda yang diperoleh adalah sebagai berikut:

$$
\begin{aligned}
& 1,314-0,053 X_{1}+0,169 X_{2}-0,295 X_{3}- \\
& \mathrm{Y}=0,166 \mathrm{X}_{4} \\
& -0,079 \mathrm{X}_{5}+0,410 \mathrm{X}_{6}
\end{aligned}
$$

Persentase sumbangan pengaruh variabel bebas terhadap variabel tidak bebas $\left(\mathrm{R}^{2}\right)$ adalah $41 \%$. Hasil tersebut mengindikasikan bahwa variasi variabel independen yang digunakan dalam model, mampu menjelaskan sebesar $41 \%$ variasi dependen. Akibatnya sebanyak 69\% variabel tidak bebas (persepsi masyarakat) dipengaruhi oleh faktorfaktor dari luar. Persentase koefisien determinasi $\left(\mathrm{R}^{2}\right)$ dapat dikatakan lemah karena kurang dari 50\%. Hal ini disebabkan persepsi masyarakat dipengaruhi oleh banyak faktor yang kompleks (Nurjanah, 2008).

Berdasarkan hasil analisis ragam (anova) dapat diketahui bahwa keenam faktor (tingkat pendidikan formal, tingkat pendidikan non formal, pendapatan, jumlah tanggungan keluarga, luas lahan garapan, dan lama tinggal) berpengaruh nyata terhadap persepsi masyarakat (Sig. 0,$041 ; \alpha=5 \%$ ). Faktor-faktor yang berpengaruh positif terhadap persepsi masyarakat adalah tingkat pendidikan non formal dan lama tinggal. Faktorfaktor yang berpengaruh negatif terhadap persepsi masyarakat adalah pendidikan formal, pendapatan, jumlah tanggungan keluarga, dan luas lahan garapan.

Tabel (Table) 1. Kategori persepsi masyarakat Desa Semoi Dua mengenai pembangunan penangkaran rusa sambar (Cervus unicolor Kerr, 1792) di KHDTK Samboja (The community's perceptions in Semoi Dua Village on sambar deer captive breeding establishment in KHDTK Samboja)

\begin{tabular}{cccc}
\hline $\begin{array}{c}\text { Interval skor persepsi } \\
\text { (Perception scores interval) }\end{array}$ & $\begin{array}{c}\text { Kategori } \\
\text { (Categories) }\end{array}$ & $\begin{array}{c}\text { Jumlah responden } \\
\text { (Number of respondents) }\end{array}$ & $\begin{array}{c}\text { Persentase } \\
\text { (Percentage) (\%) }\end{array}$ \\
\hline $\mathrm{X}>36,008$ & Baik & 0 & 0 \\
$30,326 \leq \mathrm{X} \leq 36,008$ & Sedang & 24 & 80
\end{tabular}


$X<30,326$

Buruk

6

20

Hasil uji-t menunjukkan faktor

Gangguan kawasan seperti illegal pendapatan berpengaruh nyata terhadap persepsi masyarakat (Sig. 0,038; $\alpha=5 \%$ ). Rendahnya tingkat pendapatan akan mendorong seseorang untuk membuka lahan baru dengan harapan akan menambah hasil panen yang berarti menambah pendapatan. Wajar apabila muncul kekhawatiran di antara masyarakat terhadap pembangunan penangkaran rusa sambar di KHDTK Samboja. Adanya penangkaran, akses mereka untuk membuka dan mengolah lahan akan berkurang.

Tingkat pendidikan, baik formal maupun non formal tidak berpengaruh nyata terhadap persepsi masyarakat. Walaupun tidak ada hubungan yang bermakna, Mantra (1986) menyatakan tingkat pendidikan mempunyai peranan yang penting bagi seseorang, di mana tingkat pendidikan formal sebagai modal utama untuk lebih memudahkan memulai sesuatu yang disampaikan dan pendidikan perlu proses penemuan termasuk informasi yang baru. Selain tingkat pendidikan, jumlah tanggungan keluarga, luas lahan garapan, dan lama tinggal juga tidak berpengaruh nyata terhadap persepsi masyarakat. Kondisi sosial ekonomi responden berdasarkan keempat faktor tersebut relatif sama dan lingkungan tempat tinggalnya sangat berdekatan. Hal tersebut dapat berimplikasi terhadap pemikiran responden yang cenderung sama (Fauziyah, 2009).

\section{E. Peluang Pembangunan Penang- karan Rusa sambar di KHDTK Samboja}

Berdasarkan uraian di atas, terutama tentang persepsi masyarakat, kawasan KHDTK Samboja layak dijadikan sebagai lokasi penangkaran rusa sambar untuk tujuan pelepasliaran atau guna peningkatan populasi di alam. Walaupun demikian pembangunan penangkaran rusa di dalam kawasan tersebut menghadapi tantangan yang cukup berat. masyarakat dengan kawasan yang tinggi dan kebakaran hutan merupakan beberapa kendala dalam pembangunan penangkaran. Dengan demikian pembangunan penangkaran rusa membutuhkan strategi dan pendekatan khusus, seperti melalui perangkat desa, tokoh masyarakat, dan tokoh agama.

Pembangunan dan pengembangan penangkaran rusa memerlukan partisipasi masyarakat sekitar kawasan. Partisipasi masyarakat dalam pembangunan dan pengembangan penangkaran rusa sambar dimaksudkan sebagai partisipasi masyarakat untuk mendapatkan ruang dalam suatu kegiatan yang mendukung berjalannya aktivitas tersebut. Pada tahap awal, partisipasi masyarakat dapat ditujukan untuk tujuan keamanan, di mana ada komitmen dari masyarakat untuk tidak menganggu keberadaan rusa berikut habitatnya di dalam penangkaran. Hal ini menjadi perlu, mengingat kawasan KHDTK Samboja merupakan kawasan yang rawan gangguan hutan. Usia responden yang sebagian besar merupakan usia produktif dan tingkat persepsi yang termasuk kategori "sedang” merupakan modal utama dalam partisipasi masyarakat dalam kegiatan penangkaran rusa sambar. Bercermin dari keberhasilan penangkaran rusa timor (Rusa timorensis Blainville, 1822) di Nusa Tenggara Timur, salah satunya didukung oleh unsur partisipasi masyarakat (Takandjandji et al., 2011).

Setelah tercipta kondisi penangkaran yang aman maka pada tahap selanjutnya partisipasi masyarakat dapat diarahkan ke tingkat peningkatan kesejahteraan masyarakat sekitar. Hal ini menjadi perlu mengingat tingkat pendapatan masyarakat masih rendah. Adanya kegiatan penangkaran, diharapkan tercipta alternatif pekerjaan bagi masyarakat, seperti sebagai tenaga harian atau penyedia sumber pakan bagi rusa. Pada gilirannya, 
akan terjadi hubungan timbal-balik yang positif antara kegiatan penangkaran dengan masyarakat sekitar (Setio et al., 2011; Setio, 2007). Uraian tersebut sejalan dengan pemikiran Tambunan et al. (2005) yang menyatakan bahwa segala bentuk pembangunan harus berorientasi kepada kesejahteraan masyarakat.

Dalam rangka partisipasi masyarakat di sekitar lokasi penangkaran dapat berjalan dengan baik, maka setidaknya terdapat tiga faktor utama yang harus dipenuhi, yaitu kemauan, kemampuan, dan kesempatan untuk berpartisipasi (Slamet, 1992 dalam Trison, 2005). Untuk memwujudkan hal tersebut, terutama dari pihak pengelola, diperlukan prinsip transparansi dan akuntabilitas. Transparansi berarti adanya keterbukaan penyelenggara dalam memberikan penjelasan ataupun data yang dibutuhkan masyarakat. Akuntabilitas diartikan sebagai kegiatan dan tindakan yang dilakukan oleh pihak pengelola dapat dipertanggungjawabkan secara terbuka (Munir, 2004). Hal paling utama untuk meningkatkan partisipasi masyarakat adalah melibatkan semua komponen masyarakat dalam perencanaan, pelaksanaan, dan pengontrolan.

\section{IV.KESIMPULAN DAN SARAN}

\section{A. Kesimpulan}

1. Kawasan Kawasan Hutan Dengan Tujuan Khusus (KHDTK) Samboja ditinjau dari aspek persepsi masyarakat layak untuk lokasi pengembangan penangkaran rusa sambar (Cervus unicolor Kerr, 1792) dengan tujuan pelepasliaran.

2. Persepsi masyarakat terhadap pembangunan penangkaran rusa sambar di KHDTK Samboja termasuk kategori sedang, yaitu masyarakat mendukung pengembangan penangkaran tersebut, tetapi sedikit khawatir apabila pengembangan penangkaran dapat mengganggu aktivitas berladang mereka dan mengurangi akses mereka untuk memperluas lahan, terutama di kawasan KHDTK.

3. Faktor yang mempengaruhi persepsi masyarakat secara nyata adalah pendapatan.

\section{B. Saran}

1. Perlu ada pelibatan masyarakat sekitar kawasan dalam pembangunan penangkaran rusa sambar (Cervus unicolor Kerr, 1792) di KHDTK Samboja untuk menjawab kekhawatiran hilangnya akses berladang masyarakat di dalam kawasan. Pelibatan tersebut dapat dilakukan dengan perekrutan masyarakat sekitar sebagai tenaga harian pemelihara rusa atau pencari pakan bagi rusa.

2. Perlu sosialisasi dengan bantuan pemuka masyarakat untuk mengurangi kekhawatiran masyarakat terhadap pembangunan penangkaran rusa sambar.

\section{UCAPAN TERIMAKASIH}

Ucapan terimakasih penulis sampaikan kepada kepala desa dan seluruh staf Desa Semoi Dua atas bantuan informasinya, dan Bapak Bambang yang membantu selama pengambilan data di lapangan.

\section{DAFTAR PUSTAKA}

Atmoko, T. (2007). Prospek dan kendala pengembangan penangkaran rusa sambar (Cervus unicolor (Kerr, 1792)). Prosiding Seminar "Pemanfaatan HHBK dan Konservasi Biodiversitas Menuju Hutan Lestari”, tanggal 31 Januari 2007 di Balikpapan. (pp.118-123). Samboja: Loka Litbang Satwa Primata.

Falah, F., Puspanti, A., Kasri, U., \& Suhardi. (2005). Teknologi dan kelembagaan pengembangan hutan rakyat. (Laporan Perjalanan Dinas). 
Fauziyah, E. (2009). Pengetahuan dan sikap petani terhadap upaya rehabilitasi lahan di daerah tangkapan air (DTA) Kadipaten. Tekno Hutan Tanaman 2(1), 43-52.

Garsetiasih, R. \& Takandjandji, M. (2007). Model penangkaran rusa. Prosiding Ekspose Hasil-hasil Penelitian: Konservasi dan Rehabilitasi Sumberdaya Hutan, tanggal 20 September 2006 di Padang. (pp. 35-46). Bogor: Pusat Litbang Hutan dan Konservasi Alam.

Gunawan, W., Setiabudi, D., Adinugroho, W.C., Atmoko, T., Noorcahyati, Noorhidayah, \& Hadiwibowo, $\mathrm{H}$. (2005). Rencana pengelolaan kawasan hutan dengan tujuan khusus (KHDTK) untuk hutan penelitian Samboja. Samboja: Loka Litbang Satwa Primata.

[IUCN] The International Union for Conservation of Nature. (2012). Cervus unicolor Kerr, 1792. Diakses 26 April 2013 dari www.iucnredlist.org.

Kuswanda, W. (2006). Pola pemanfaatan lahan masyarakat di daerah penyangga Taman Nasional Bukit Tiga Puluh, Provinsi Jambi. Jurnal Penelitian Hutan dan Konservasi Alam III(3), 249-258.

Manshur, A. (2011). Studi pakan dan perilaku makan rusa sambar (Cervus unicolor (Kerr, 1792)) di Resort Teluk Pulai, Taman Nasional Tanjung Puting, Kalimantan Tengah. (Skripsi). Fakultas Kehutanan IPB.

Mantra, I.B. (1986). Perencanaan penyuluhan kesehatan masyarakat. Jakarta: Pusat Penyuluhan Kesehatan Masyarakat.

Ma'ruf, A., Atmoko, T., \& Syahbani, I. (2006). Teknologi penangkaran rusa sambar (Cervus unicolor (Kerr, 1792)). Prosiding Gelar dan Dialog Teknologi : Teknologi untuk Kelestarian Hutan dan
Kesejahteraan Masyarakat, tanggal 29-30 Juni 2005 di Mataram. (pp. 57-68). Bogor: Puslitbang Hutan dan Konservasi Alam.

Mindawati, N. (2006). Sekilas tentang hutan penelitian. Prosiding Gelar dan Dialog Teknologi: Teknologi untuk Kelestarian Hutan dan Kesejahteraan Masyarakat, tanggal 29-30 Juni 2005 di Mataram. Bogor: Pusat Litbang Hutan dan Konservasi Alam.

Munir, D.A. (2004). Ada tiga pilar dalam menumbuhkan partisipasi masyarakat. Majalah Gedeha (Gema Desa Hutan). Edisi XIV, Februari.

Nurjanah. (2008). Modul pelatihan SPSS (Statistical Package for the Social Science). Malang.

Peraturan Pemerintah Nomor 7 Tahun 1999 tentang Pengawetan Jenis Tumbuhan dan Satwa.

Prasetya, D. (2010). Kualitas manusia kunci dividen demografi. Diakses 15 Oktober 2010 dari http://bataviase.co.id/node/141158.

Riana, N. (2013). Perubahan penutupan lahan Kawasan Hutan Dengan Tujuan Khusus (KHDTK) Samboja berdasarkan citra landsat 7+ ETM tahun 2010 dan 2013. (Skripsi). Universitas Tujuh Belas Agustus. Samarinda. Tidak dipublikasikan.

Santoso, S. I. \& Fanani, Z. (2009). Evaluasi penangkaran rusa timor (Cervus timorensis Blainville, 1822) di Pulau Jawa. Seminar Nasional Kebangkitan Peternakan. Semarang, 20 Mei 2009.

Saragih, G.S. (2007). Sikap masyarakat Kelurahan Pancoran Mas terhadap Taman Hutan Raya Pancoran Mas, Depok. (Skripsi). Departemen Konservasi Sumber Daya Alam dan Ekowisata-IPB.

Setio, P., Bismark, M., \& Subiandono, E. (2011). Pembangunan pusat pengembangan teknologi penangkaran rusa. Dalam A. S. 
Mukhtar, M. Bismark, S. A. Siran, A.D. Ismanto (eds), Sintesis Hasilhasil Litbang Pengembangan Penangkaran Rusa Timor (Rusa timorensis Blainville, 1822). Jakarta: Badan Penelitian dan Pengembangan Kehutanan.

Setio, P. (2007). Penangkaran rusa. Prosiding Ekspose dan Gelar Teknologi: Pemanfaatan IPTEK untuk Mendukung Pembangunan Daerah dan Kesejahteraan Masyarakat Propinsi Kalimantan Barat, tanggal 11-13 Desember 2007 di Pontianak. (pp. 49-65). Bogor: Puslitbang Hutan dan Konservasi Alam.

Singarimbun, M. \& Effendi, S. (1995). Metode penelitian survei. Yogyakarta: Lembaga Penelitian, Pendidikan, dan Penerangan Ekonomi dan Sosial.

Suba, R.B., Boer, C., \& Irman. (2010). Informasi dari feses dan jejak kaki rusa sambar (Cervus unicolor (Kerr, 1792))) serta implikasinya pada akurasi penaksiran populasi. Jurnal Ilmu Kehutanan IV(2), 7079.
Sugiyono \& Wibowo, E. (2004). Statistika untuk penelitian dan aplikasinya dengan SPSS 10.0 for Windows. Bandung: Alfabeta.

Takandjandji, M., Garsetiasih, R., \& Kayat. (2011). Pengembangan penangkaran rusa. Dalam A. S. Mukhtar, M. Bismark, S. A. Siran, A.D. Ismanto (eds), Sintesis Hasilhasil Litbang Pengembangan Penangkaran Rusa Timor (Rusa timorensis Blainville, 1822). Jakarta: Badan Penelitian dan Pengembangan Kehutanan.

Tambunan, R., Harahap, R.H., \& Lubis, Z. (2005). Pengelolaan hutan mangrove di Kabupaten Asahan (studi kasus partisipasi masyarakat dalam pengelolaan hutan mangrove di Kecamatan Lima Puluh, Kabupaten Asahan). Jurnal Studi Pembangunan 1(1), 55-59.

Trison, S. (2005). Pengembangan partisipasi masyarakat dalam kegiatan rehabilitasi hutan (kasus di Hutan Pendidikan Gunung Walat, Sukabumi). (Tesis). Sekolah Pascasarjana Institut Pertanian Bogor. 